'Atkinson, A. J., and Carroll, W. W., Fournal of the American Medical Association, 1964, 188, 183.

-Warren, K. W., Athanassiades, S., and Monge, J. I., American Fournal of Surgery, 1966, 111, 23.

- Grua, O. E., and McMurrin, J. A., American Fournal of Surgery, 1968, 116, 659.

10 Kasai, M., and Watanabe, I., Cancer, 1970, 25, 551.

\section{Pulmonary Alveolar Proteinosis}

In $1958 \mathrm{~S}$. H. Rosen and colleagues ${ }^{1}$ described what they considered to be a "remarkable disease of the lung that consists of the filling of the alveoli by a PAS-[periodic acid Schiff] positive proteinaceous material, rich in lipid." In these distal air spaces there is little if any cellular reaction. While this histological picture is the essential diagnostic feature of the disease, in clinical practice the condition is suggested by the radiographic appearances. To quote again from the original description: "There is a fine, diffuse, perihilar, radiating, feathery or vaguely nodular, soft density, resembling ... the pattern seen in severe pulmonary edema." These descriptions are still unchanged following reports now of over 150 cases in the world literature. The radiograph reflects irregular diffuse alveolar consolidation, which is the basis of the lung disturbance.

Clinically there may be few symptoms or signs to accompany a dramatic chest radiograph, but usually there is some shortness of breath, in part due to restriction of ventilation but mainly dependent on impaired gas transfer. Airways obstruction is not present. The patient may have some cough and produce scanty, usually mucoid, sputum. This may contain lipoproteinaceous material from the alveoli. ${ }^{2}$

It is a chronic disease and its natural history as shown in the records of 139 patients has been reviewed by J. M. Davidson and W. M. Macleod. ${ }^{3}$ The patients, more men than women, were aged from infancy to 72 years but were mostly between 30 and 50 . During varied periods of observation 48 of them recovered or greatly improved. Forty-five patients died, and in 38 of these cases death was directly due to the proteinosis or its complications. Infections were a common complication, especially fungalfor example, nocardiosis.

Looking for a causative factor Rosen and his colleagues could find no common occupational risk. Several patients were exposed to wood dusts, others to a wider variety of dusts and fumes, but many admitted no exceptional dust exposure. Experimentally a similar alveolar reaction has been found in rats exposed to siliceous dusts. ${ }^{45}$ In man similar features have been seen in silicosis, ${ }^{6}$ especially in the acute form, ${ }^{7}$ and even in tuberculosis, ${ }^{8}$ though here the affected alveoli are few and scattered. A further puzzle is the experimental response in rats to the same dusts, which on one occasion led to silicosis and on another produced lipoproteinosis. ${ }^{4}$ This suggests that an additional factor is required for its development. There is no evidence of an infective agent. The similarity of the alveolar reaction to that produced by the protozoon Pneumocystis carinii was noted by Rosen and his colleagues, but careful studies have excluded this as a possible infective agent. J. Gough 6 suggested that its production might depend in part on an altered state of immunity, and clinical support for this view is evident from the behaviour of the disease in children. A. R. Colon and colleagues, 9 studying the presentation in 23 infants, noted the frequent occurrence of lymphopenia, immunoglobulin deficiencies, and thymic alymphoplasia.

The source and nature of the intra-alveolar material is still in doubt. Rosen and his colleagues considered that much of it was formed by transformation of the septal cells, which, increasing in number, slough off and, disintegrating, fill the alveoli with the periodic-acid-Schiffpositive floccular, granular substance. More recent investigations show that some of these alveolar cells are phagocytic macrophages ingesting the lipid material, which in turn is derived from the type 11 or B granular pneumonocytes. These alveolar lining cells are considered to be the source of lung surfactant, and it appears that this substance accumulates in the alveoli either from overproduction ${ }^{10}$ or more likely as a result of inadequate clearing. ${ }^{11}$ Serum proteins have also been identified in the alveolar substance, suggesting that transudation of serum plays a part. ${ }^{4}$ Whether desquamative interstitial pneumonia, ${ }^{12}$ a condition in which the alveoli are filled with granular pneumonocytes and macrophages, is a related disorder remains to be determined.

While some patients recover spontaneously, it is still a disease with a high risk of progression, severe lung damage, and death. With so little known of its development, prevention is impossible to direct and treatment remains empirical. It would seem that antibiotics should be prescribed only when directly indicated. Corticosteroids should remain a last resort. There is an encouraging response in a worsening situation to pulmonary lavage. ${ }^{13}$

Pulmonary alveolar proteinosis is a newly recognized lung reaction rather than a new lung disease. Before the availability of modern histochemical techniques the reaction, so resembling pulmonary oedema, could easily have been overlooked. The search is now not for a new cause of death but for a finer understanding of the behaviour of the alveolus by work in the laboratory and by alert observation in clinical practice.

1 Rosen, S. H., Castleman, B., and Liebow, A. A., New England fournal of Medicine, 1958, 258, 1123.

Carlson, D. J., and Mason, E. W., American fournal of Clinical Pathology,

$1960,33,48$.
3 Davidson, J. M., and Macleod, W. M., British fournal of Diseases of the Chest, 1969, 63, 13.

4 Heppleston, A. G., Wright, N. A., and Stewart, J. A., Fournal of Pathology, $1970,101,293$.

5 Corrin, B., and King, E., Thorax, 1970, 25, 230.

Gough, J., British Medical fournal, 1967, 1, 629.

7 Buechner, H. A., and Ansari, A., Diseases of the Chest, 1969, 55, 274.

8 Buechner, H. A., and Ansari, A., Diseases of the

8 Steer, A., Archives of Pathology, 1969, 87, 347.
' Colon, A. R., Lawrence, R. D., Mills, S. D., and O'Connell, E. J American fournal of Diseases of Children, 1971, 121, 481.

${ }^{10}$ Larson, R. K., and Gordinier, R., Annals of Internal Medicine, 1965, 62, 292.

11 Ramirez-R., J., and Harlan, W. R., American Fournal of Medicine, 1968, 45, 502 .

12 Liebow, A. A., Steer, A., and Billingsley, J. G., American fournal of Medicine, 1965, 39, 369.

13 Ramirez-R., J., American Review of Respiratory Diseases, 1971, 103, 666.

\section{Congenital Pulmonary Lymphangiectasis}

Cystic disease of the lungs due to dilatation of the lymphatic vessels is one of the lesser known forms. The condition, known usually as congenital pulmonary lymphangiectasis, is characterized by intercommunicating thin-walled, endo- 